\title{
Evaluation of the Position of Lingula Mandible, Mental Foramen and Lingual Foramen of Individuals in the 7-17 Age Groups Via Cone-Beam Computed Tomography
}

\author{
Duygu Goller Bulut $\mathbb{D}^{\text {, Seval Bayrak }}$ \\ Bolu Abant Izzet Baysal University, Faculty of Dentistry, Department of Dentomaxillofacial Radiology, Bolu, Turkey.
}

Correspondence Author: Seval Bayrak

E-mail: dtseval@hotmail.com

Received: 14.03 .2020

Accepted: 14.06 .2021

\begin{abstract}
Objective: The identification of landmarks in mandible is an important stage before dental procedures in pediatric patients. The purpose of this study was to determine the location of lingula mandible, mental foramen (MF) and lingual foramen (LF) in a pediatric population.

Methods: The distance of lingula mandible to the anterior, posterior, superior, and inferior borders of mandible and to distal edge of the alveolar socket of the 1st molar tooth were measured in 296 cone-beam CT. MF and LF distance to the top of the alveolar crest and the inferior edge of the basis mandibulae were determined. The horizontal location of MF was evaluated.

Results: The distance between lingula mandible and the sigmoid notch, the inferior border of the ramus, the anterior border of the ramus and

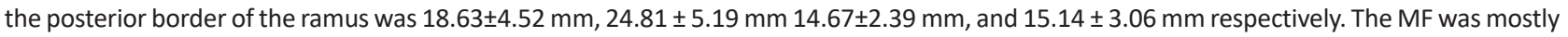
located between long axes of first and second premolar teeth. LF is closer to the inferior edge of the basis mandibulae.

Conclusion: It is necessary to determine anatomical landmarks in children prior to the surgical operations to prevent the possible neurovascular complications.
\end{abstract}

Keywords: anatomic landmarks, cone beam computed tomography, lingual foramen, lingula, mental foramen.

\section{INTRODUCTION}

Knowing the actual location of anatomic structures containing neurovascular bundles in children is important to minimize the risk of transient or permanent nerve damage during anaesthesia before operations such as comprehensive restorative therapies, surgical procedures, treatment of mandibular fractures and orthognathic surgery $(1,2)$. These important anatomical landmarks in children have been reported as; incisive canal, mental foramen (MF), mandibular canal and lingual foramen (LF) (3).

Neurovascular structures in the mandible begin with the mandibular foramen (ManF). Lingula mandible is a reliable anatomical landmark used to determine the position of ManF. Lingula is a tongue-shaped bone protrusion that forms the medial border of the MF on the medial surface of the mandible. Due to its close proximity to ManF and neurovascular nerve bundles, it is an important anatomical landmark during maxillofacial surgery and is used to avoid nerve during inferior alveolar nerve block anaesthesia (4). Lingula mandible is also an important marker of sagittal splitramus osteotomy. During sagittal split-ramus osteotomy, the horizontal cut of the mandible is made just above the lingula (5). In the literature, it is reported that the location of the lingula mandible is variable $(4,6)$. This variation refers to a specific risk of injury to the inferior alveolar nerve $(7,8)$. In a study on children of different ethnic background has reported that the ManF moves horizontally in a growing mandibular ramus in anterior or posterior direction or remains stable (9).

Neurovascular structures are opened to the outside of the bone structure through the MF in the premolar region on both sides of the mandible. The location of mental foramina in children can be determined radiographically or by clinical palpation (10). In the summary of the literature, according to the Green classification, mental foramen in children are mostly localized in the premolar area (11). In children, the MF is closer to the alveolar crest and migrates to the middle triple and lower triple region in vertical direction and posteriorly / distally in horizontal direction with the development of the dentition. (12). This change in position is thought to be caused by a combination of bone growth in the region and mesial drift of the dentition $(9,12)$.

The neurovascular structures are opened out of the bone again in the LF region of the mandible. The LF is usually at the level of the mandibular symphysis, at the level of or above 
the mental spines, and includes an artery developing from the anastomosis of the two sublingual arteries. It includes the lingual artery, sublingual artery, mandibular incisive nerve, branches of the mylohyoid nerve and lingual nerve (13). In children, the number and localization of the LF are important in surgical procedures such as genioplasty, orthognathic surgery, during graft removal of the jawbone, and for screw and/or plaque placement in mandibular rehabilitation after trauma in the anterior region (14).

The reliability of the definition of anatomical landmark in children is influenced by various factors such as the intensity and sharpness of the images, the anatomical complexity, and superposition of the tissues, the classification of landmark and the experience of observers. The cone-beam CT (CBCT) has a number of tools, allowing 3-D image reproduction in all directions to allow correct identification of landmarks. Previous studies reported excellent accurateness with CBCT $(15,16)$. The size and morphology of the anatomical structure can be easily evaluated with 3D images obtained by CBCT.

The aim of this study was to evaluate the position of mandibular lingula, mental foramina and LF and the prevalence of accessory MF and LF in patients with pediatric age group by CBCT.

\section{METHODS}

The study was ethically approved by the Bolu Abant Izzet Baysal University Clinical Research Ethics Committee (Decision no:2018/291)

296 CBCT images which belonged to the pediatric age group patients (age range between 7 and 17 years) were randomly selected from the existing archive of the Department of Oral and Maxillofacial Radiology at the Bolu Abant İzet Baysal University. CBCTs of the patients were taken for reasons such as embedded teeth, supernumerary teeth, pathology, orthodontic treatment and temporomandibular joint (TMJ) problem. The patients who had pathology in area of interest, Class III malocclusion and mandibular asymmetry were excluded from the study.

$\mathrm{CBCT}$ images were taken with the same exposure parameters (120 kVp, $15 \mathrm{~mA}, 0.3 \mathrm{~mm}^{3}$ voxel size and $4.8 \mathrm{sec}$ ) with I-CAT CBCT System (Imaging Sciences International, Hatfield, PA, USA). CBCTs which the entire mandible enters the image area, the relevant regions can be seen clearly in all sections and have no image artefact were evaluated.

All CBCTs were evaluated on 3 different anatomic landmark regions on the right and left sides on the mandible and following measurements were recorded: 1 . Lingula of mandible, 2. Mental foramen and 3. Lingual foramen:

1. Lingula of Mandible (ML): Measurements of the lingula mandible were made on $3 \mathrm{D}$ CBCT images on the inner surface of the mandible.

ML-MA: Anterior distance by drawing a horizontal line between the most peak of the $\mathrm{ML}$ and the most anterior point of the ramus mandible (MA);
ML-MP: Posterior distance by drawing a horizontal line between the peak of the ML and the most posterior point of the ramus mandible (MP);

ML-MS: The superior distance by drawing a vertical line between the peak of the $\mathrm{ML}$ and the lowest point of the sigmoid notch;

ML-MI: Lower length by drawing a vertical line between the peak of the $M L$ and the most inferior point of the ramus mandible (MI);

ML-1. Molar: The occlusal distance was measured between the peak of ML and the most distal edge of the alveolar socket of the 1st molar tooth, as millimetres (Figure $1 \mathrm{~A}-\mathrm{F}$ ). (15)
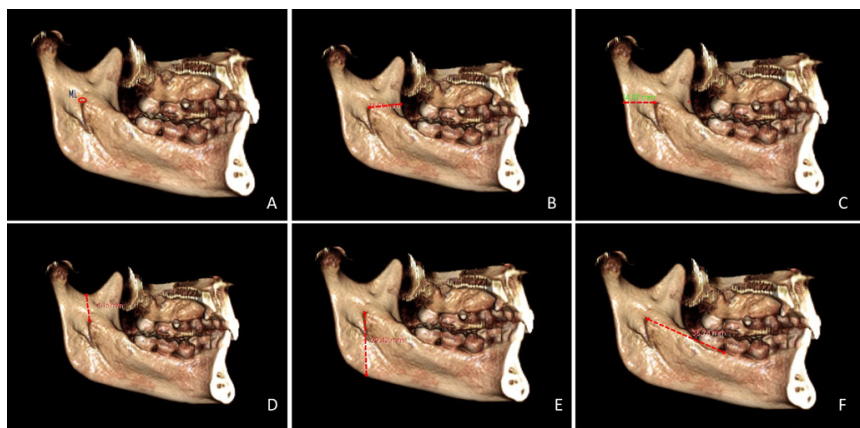

Figure 1. Measurements of lingula mandible were performed in threedimensional. A. Location of ML (red circle), B. ML-MA: Distance of the lingula to the anterior of the mandible, C. ML-MP: Distance of the lingula to the posterior of the mandible, D. ML-MS: Distance of the lingula to the superior border of the mandible, E. ML-MI: Distance of the lingula to the inferior border of the mandible, F. ML-1. Molar: Distance of the lingula to the most distal edge of the alveolar socket of the 1st molar tooth.

2. Mental foramen: On the cross-section images obtained from the midpoint of the MF, the distance between the upper limit of the MF and the top of the alveolar crest and the distance between the lower border of the MF and the lower edge of the basis mandible were measured in millimetres. (Figure 2A) (17).
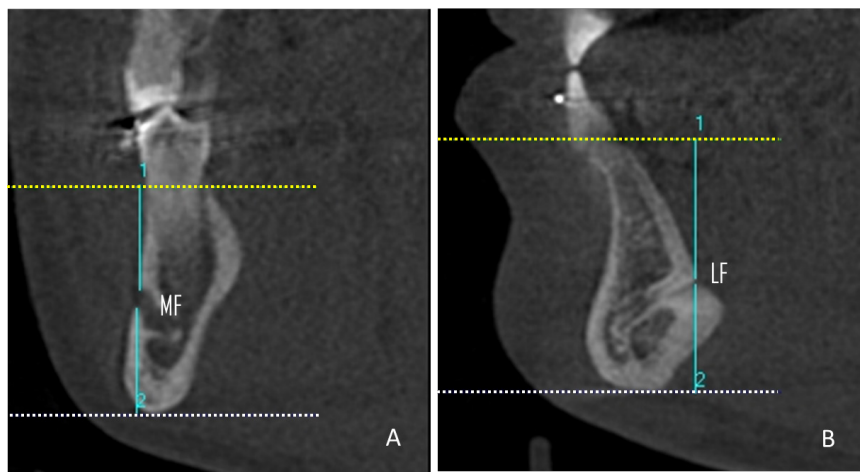

Figure 2. A. Measurements of the distance between the upper limit of the mental foramen (ML) and the top of the alveolar crest and the distance between the lower border of the mental foramen and the lower edge of the basis mandibulae on the cross-section images, $B$. Measurements of the distances of the lingual foramen (LF) to the top of the alveolar crest and the lower edge of the basis mandibulae in sagittal sections. 
5 points were determined in order to evaluate the horizontal localization of the MF (18);

- Point: Front of the long axis of the 1. premolar

- Point: At the level of the long axis of the 1. premolar Point: Between long axes of 1., and 2. premolar

- Point: At the level of the long axis of the 2. premolar

- Point: Located at distal side of the long axis of the second premolar

The accessory MF presence for both sides was recorded in each image.

3. Lingual foramen: In sagittal sections, the distances of the LF to the top of the alveolar crest and the lower edge of the basis mandible were measured and the presence of accessory LF was evaluated (Figure 2B) (19).

All measurements were performed independently by two observers. Observers were calibrated by measuring $10 \%$ of images at the beginning of the study. If the observations between 2 observers differ by more than $2 \mathrm{~mm}$, a consensus was obtained and a kappa score was determined (ranged from 0.85 to 1.00). After all measurements were completed, 2 observers re-evaluated $20 \%$ of the CBCT images and the kappa score was ranged from 0.91 to 1.00 . In the statistical analysis, the mean of both observers' measurements was used.

\section{Statistical Analysis}

The sample size was calculated based on the previous study (15), considering Type I errors (0.05), targeted power $(0.80)$ and effect size $(0.50)$ due the distance of lingula from posterior border of ramus $(p<0.05)$ by $G^{*}$ power 3.1.9.4 software program (Heinrich Heine University, Dusseldorf, Germany). Statistical software package SPSS version 20 (IBM Corp, New York, NY, USA) was used to analyze obtained data. Descriptive values were assessed by using descriptive statistics. T-tests were used to analyse data according to side and gender. The significance level was set as $p<0.05$.

\section{RESULT}

A total of 296 patients (120 male, 176 female) age ranging from 7 to 17 years (mean $14.26 \pm 1.91$ ) were included in the study. Descriptive values of the measurements of lingula are shown in Table 1. The measurements were performed separately for the right and left sides of each patient, and there was no significant difference between the right and left and between the genders in lingula measurements $(P>$ $0.05)$. The lingula was located at $18.63 \pm 4.52 \mathrm{~mm}$ from the sigmoid notch, $24.81 \pm 5.19 \mathrm{~mm}$ from the inferior border of the ramus, $14.67 \pm 2.39 \mathrm{~mm}$ from the anterior border of the ramus and $15.14 \pm 3.06 \mathrm{~mm}$ from the posterior border of the ramus. The mean distance to the distal surface of the alveolar socket of the mandibular 1. molar from the lingula from was $34.88 \pm 4.23 \mathrm{~mm}$.

The results of the vertical and horizontal position of the right and left mental foramina were shown in Table 2 and Table 3, respectively. On the right and left sides, the MF was at the highest (66.9\% and $74.3 \%$, respectively) in the 3. Point region; between long axes of first and second premolar teeth. This is followed by the 4. Point region; at the level of the long axis of the second premolar teeth. No significant difference was found between sides in MF measurements $(P>0.05)$. Gender difference was found only for the distance between the MF and the lower edge of the mandible $(P<0.001)$.

Table 4 shows the measurement results of the distance of the LF to the alveolar crest and the inferior edge of the basis mandible. The LF was found to be closer to the inferior edge of the basis mandible (11.68 $\pm 4.26 \mathrm{~mm})$. In $7.1 \%$ of cases, accessory LF was observed (Table 5). No significant difference was found between sides and gender in LF measurements $(P>0.05)$.

Table 1. Distance of lingula mandible from various mandibular landmarks

\begin{tabular}{|c|c|c|c|c|c|c|}
\hline & & & Minimum & Maximum & Mean & $\begin{array}{c}\text { Std. } \\
\text { Deviation }\end{array}$ \\
\hline & ML-MS & \multirow{4}{*}{148} & 9,64 & 30,72 & 18,63 & 4,52 \\
\hline & ML-MI & & 12,62 & 37,27 & 24,81 & 5,19 \\
\hline \multirow[t]{5}{*}{ Right } & ML-MA & & 8,57 & 21,06 & 14,67 & 2,39 \\
\hline & ML-MP & & 9,19 & 30,12 & 15,14 & 3,06 \\
\hline & ML-1. molar & \multirow{6}{*}{148} & 19,90 & 46,39 & 34,88 & 4,23 \\
\hline & ML-MS & & 11,20 & 41,14 & 18,79 & 4,84 \\
\hline & ML-MI & & 9,85 & 38,17 & 25,16 & 5,58 \\
\hline \multirow[t]{3}{*}{ Left } & $\mathrm{ML}-\mathrm{MA}$ & & 0,00 & 20,47 & 14,96 & 2,82 \\
\hline & $M L-M P$ & & 9,21 & 24,68 & 14,12 & 2,70 \\
\hline & $\mathrm{ML}-1$. molar & & 21,91 & 45,14 & 35,74 & 4,37 \\
\hline
\end{tabular}

N: Number, Std: Standard. ML: Mandibular Lingula, MS: Superior border of mandible, MI: Inferior border of mandible, MA: Anterior border of mandible, MP: posterior border of mandible.

Table 2. Vertical location of the mental foramen (MF)

\begin{tabular}{|c|c|c|c|c|c|c|}
\hline & & $\mathbf{N}$ & Minimum & Maximum & Mean & $\begin{array}{c}\text { Std. } \\
\text { Deviation }\end{array}$ \\
\hline \multirow{2}{*}{ Right } & $\begin{array}{c}\text { MF- } \\
\text { inferior } \\
\text { border }\end{array}$ & \multirow{2}{*}{148} & 7,80 & 17,70 & 12,68 & 1,80 \\
\hline & $\begin{array}{c}\text { MF - } \\
\text { Alveolar } \\
\text { crest }\end{array}$ & & 4,80 & 17,70 & 12,23 & 2,32 \\
\hline \multirow{2}{*}{ Left } & $\begin{array}{c}\text { MF- } \\
\text { inferior } \\
\text { border }\end{array}$ & \multirow{2}{*}{148} & 8,41 & 16,20 & 12,41 & 1,58 \\
\hline & $\begin{array}{c}\text { MF - } \\
\text { Alveolar } \\
\text { crest }\end{array}$ & & 5,71 & 23,77 & 12,42 & 2,65 \\
\hline
\end{tabular}

N: Number, Std: Standard. 
Table 3. Horizontal location of the mental foramen

\begin{tabular}{llllll} 
Side & Point & Point & Point & Point & Point \\
\hline Right & $4(2,7 \%)$ & $12(8,1 \%)$ & $99(66,9 \%)$ & $29(19,6 \%)$ & $4(2,7 \%)$ \\
Left & $2(1,4 \%)$ & $7(4,7 \%)$ & $110(74,3 \%)$ & $26(17,6 \%)$ & $3(2 \%)$ \\
\hline
\end{tabular}

Point; In front of long axis of the first premolar tooth

Point; In line with the long axis of the first premolar tooth

Point Between long axes of first and second premolar teeth

Point; In line with the long axis of the second premolar tooth

Points; Distal of the long axis of the second premolar tooth

Table 4. Location of lingual foramen

\begin{tabular}{cccccc}
$\begin{array}{c}\text { Distance to } \\
\text { Inferior border of } \\
\text { mandible }\end{array}$ & $N$ & Minimum & Maximum & Mean & $\begin{array}{c}\text { Std. } \\
\text { Deviation }\end{array}$ \\
Alveolar crest & 148 & 1,20 & 19,20 & 11,68 & 4,26 \\
\hline
\end{tabular}

N: Number, Std: Standard.

Table 5. Prevalence of accessory lingual foramen

\begin{tabular}{rcc} 
Accessory Lingual Foramen & Frequency & Percent (\%) \\
Absent & 275 & 92,9 \\
Present & 21 & 7,1 \\
\hline
\end{tabular}

\section{DISCUSSION}

Craniofacial imaging techniques with $\mathrm{CBCT}$ are becoming increasingly popular and have introduced new directions to morphological evaluation $(20,21)$. In this study, anatomical landmarks in the mandible were evaluated on multiplane reconstructed CBCT images of the pediatric population.

Lingula mandible is an important clinical marker and the location of lingula varies according to various ethnic and racial groups $(7,22-24)$. There are several studies in the literature measuring the distance of the lingula mandible to the specific points in the mandible. In studies evaluating the distance of the lingula mandible from the anterior of the mandible (ML-MA distance) on the adult population; Senel et al. (21) reported as $18.5 \pm 2.3 \mathrm{~mm}$, Sheonoy et al. (25) as 16 $\mathrm{mm}$, Samantha and Kharb (26) as $20.0 \pm 2.4 \mathrm{~mm}$, Sekerci and Sisman (27) as $16.77 \pm 2.74 \mathrm{~mm}$, and Jansisyanot et al. (8) as $20.6 \pm 3.5 \mathrm{~mm}$. Sekerci et al. (15) reported the same distance in the pediatric population as $13.3 \pm 2.3 \mathrm{~mm}$. In this study, the mean ML-MA distance was $14.82 \pm 2.61 \mathrm{~mm}$. This result was similar to Sekerci et al. (15) but lower than the results of other studies and the possible reason is that the mandible is smaller in children.

In previous studies, the ML-MP distance was reported as 16.9 $\pm 3.5 \mathrm{~mm}$ (21), $15 \pm 2.7 \mathrm{~mm}(26)$, and $10.2 \pm 1.6 \mathrm{~mm} \mathrm{(15);}$ ML-MS distance was reported as18.1 $\pm 3.6 \mathrm{~mm}(21), 15.4 \pm$ $2.7 \mathrm{~mm}(26), 15.32 \pm 2.46 \mathrm{~mm}(27), 16.6 \pm 2.9 \mathrm{~mm}$ (8), and $16.6 \pm 2.9 \mathrm{~mm}(15) ; \mathrm{ML}-\mathrm{MI}$ distance as $38.3 \pm 5.3 \mathrm{~mm}(21)$ and as $23.1 \pm 3.2 \mathrm{~mm}(15)$. In this study, the mean ML-MP, ML-MS, and ML-MI distances were $14.63 \pm 2.93,18.71 \pm 4.68$ and $24.99 \pm 5.38$, respectively. These findings are similar to those of Sekerci et al. (15). However the numerical differences between the other studies might be due to the difference in the average age of the populations.

The mean distance of the $M L$ to the distal surface of the alveolar socket of the mandibular 1 . molar tooth was 35.31 $\pm 4.31 \mathrm{~mm}$ in the present study as higher which reported by Sekerci et al. (15) as $24.7 \pm 3.7 \mathrm{~mm}$. The difference in the results may be due to the higher mean age as $14.26 \pm 1.91$ years of the patient population in this study.

There is general evidence that lengths of anatomical structures are shorter than or equal to men in women. Sekerci and Sisman (27) reported that some measurements for location of lingula were higher in males. On the contrary, Jung et al. (4) reported that the location of lingula did not show a statistically significant difference between the genders. Similar to Jung et al. (4), in this study, there were no significant differences in the measurements between genders.

As reported in previous studies, the location of the mental foramina shifts distally along with the growth of the mandible $(12,28,29)$. In our study, one MF was detected on both sides of all children, and on the right and left sides, respectively, $66.9 \%$ and $74.3 \%$ of MFs located between long axes of 1. , and 2. premolar teeth; $19.6 \%$ and $17.6 \%$ located in line with the long axis of the 2. premolar tooth. Similarly in Lim et al.'s study (9) a single MF was observed in all children and were located between the root apices of the 1. and 2. premolars followed by the root apex of the 2. premolar. On Caucasian children, Gerhenson and colleagues (30) analyzed children in primary and mixed dentition, and children before the eruption of teeth. In children in mixed dentition, MF was commonly located at the root apex of the first premolar $(48 \%)$ and between the root apices of the first and second premolar (34\%). Assuming that the children in this study were in the mixed dentition period, this location difference may be caused by racial difference.

Gershenson et al. (30) reported that the position of the MF was closer to the upper borders in the primary dentition in children and decreased to the middle third of the mandible during the mixed dentition. They also stated that the MF was positioned closer to the inferior border of the mandible in adults. In this study, the distance between the MF and the inferior border of the mandible was $12.68 \pm 1.80$ on the right side and $12.41 \pm 1.58 \mathrm{~mm}$ on the left side. Similarly, Gungor et al. (31) reported similarly on both sides in a population age range between 10-70 years. Also, similar results have been reported in a study conducted in the Turkish population; $12.86 \pm 1.55 \mathrm{~mm}$ on the right and $13.13 \pm 1.89 \mathrm{~mm}$ on the left) (17). This similarity in the results may be due to the fact that the measurements were made on similar populations. In a study of skulls, Udhaya et al. (18) reported this distance as similar mean value. Neiva et al. (32) reported lower value and Apinhasmit et al. (33) reported higher value in males and in females. This difference may be because of this that 
they measured the distance between the inferior border of the mandible and the middle of the MF, but we measured the distance between the inferior border of the MF and the inferior border of the mandible.

Gungor et al (31) reported the distance between the top of the alveolar crest and the MF as $13.22 \pm 2.76 \mathrm{~mm}$ and 13.36 $\pm 2.84 \mathrm{~mm}$ on the left and right sides, respectively. Udhaya et al. (18) found as $12.02 \pm 2.48 \mathrm{~mm}$ and $12.21 \pm 2.61 \mathrm{~mm}$ on the right and left sides, respectively. Caglayan et al. (17) gained $12.08 \pm 3.12 \mathrm{~mm}$ on the left and $11.86 \pm 2.75 \mathrm{~mm}$ on the right. In all studies, the difference compared to our results $(12.23 \pm 2.32 \mathrm{~mm}$ on the right and $12.42 \pm 2.65 \mathrm{~mm}$ on the left) was 1-2 mm. No difference was found between the sides in the measurement between the MF and the top of the alveolar crest not only in our study $(P=0.508)$ but also in that by Gungor et al. (31) and Caglayan et al. (17). However, in both studies, gender difference was found in the distance of the MF to the inferior border of the mandible and the alveolar crest $(P \leq 0.01)$. In our study, the gender difference was found only for the distance measurement between the inferior edge of the mandible and the MF $(P<0.001)$.

As stated in several cadaver studies (19,34-36), neurovascular structures come into the mandible through the LF and so there is a risk during mandibular surgery in this region. The present study showed a mean distance of $11.68 \mathrm{~mm}$ from the inferior mandibular border to the LF. This finding is lower than those reported by Mraiwa et al. (37) (12.3) and Makris et al. (19) $(12.28 \mathrm{~mm})$. While, this mean distance is higher than in many other studies (10.0 mm (38), $10.2 \mathrm{~mm},(39)$ and $10.6 \mathrm{~mm}$ (35). These numerical differences between studies may depend on the distribution of population, race and methodology. In addition, accessory LF was found in $7.1 \%$ of the cases in the study. We think that the possibility of an accessory foramen and canal should not be ignored during surgical interventions in the relevant region.

The present study results provide navigational information during dental procedures of the mandible. Clinicians should insert a needle approximately $14.6 \mathrm{~mm}$ from the anterior border of the ramus and approximately $24.81 \mathrm{~mm}$ from the lower border of the ramus while performing mandibular nerve block anaesthesia on pediatric patients. The high rate of mental foramen being between the 1st and 2nd premolar teeth in children and the presence of accessory lingual foramen should be taken into account during dental procedures to avoid vascular and nerve damage.

In conclusion, the identification of anatomical landmark in children is an important stage before dental procedures and the location of the landmarks may show differences according to race, age, gender, dentition, and growth pattern. Detailed evaluation of anatomical structures with CBCT in children is important to prevent complications in order not to damage neurovascular structures before surgical procedures.

\section{REFERENCES}

[1] da Fontoura RA, Vasconcellos HA, Campos AE. Morphologic basis for the intraoral vertical ramus osteotomy: anatomic and radiographic localization of the mandibular foramen. J Oral Maxillofac Surg 2002;60:660-665.

[2] Trost O, Salignon V, Cheynel N, Malka G, Trouilloud P. A simple method to locate mandibular foramen: preliminary radiological study. Surg Radiol Anat 2010;32:927-931.

[3] Cantekin K, Sekerci AE, Miloglu O, Buyuk SK. Identification of the mandibular landmarks in a pediatric population. Med Oral Patol Oral Cir Bucal 2014;19:e136-41.

[4] Jung $\mathrm{YH}$, Cho BH, Hwang JJ. Location and shape of the mandibular lingula: Comparison of skeletal class I and class III patients using panoramic radiography and cone-beam computed tomography. Imaging Sci Dent 2018;48:185-190.

[5] Cillo JE, Stella JP. Selection of sagittal split ramus osteotomy technique based on skeletal anatomy and planned distal segment movement: current therapy. J Oral Maxillofac Surg 2005;63:109-114.

[6] Fujimura K, Segami N, Kobayashi S. Anatomical study of the complications of intraoral vertico-sagittal ramus osteotomy. J Oral Maxillofac Surg 2006;64:384-389.

[7] Kositbowornchai $S$, Siritapetawee $M$, Damrongrungruang T, Khongkankong W, Chatrchaiwiwatana S, Khamanarong $K$. Shape of the lingula and its localization by panoramic radiograph versus dry mandibular measurement. Surg Radiol Anat 2007;29:689-694.

[8] Jansisyanont P, Apinhasmit W, Chompoopong S. Shape, height, and location of the lingula for sagittal ramus osteotomy in Thais. Clin Anat 2009;22:787-793.

[9] Lim MY, Lim WW, Rajan S, Nambiar P, Ngeow WC. Age-related changes in the location of the mandibular and mental foramen in children with Mongoloid skeletal pattern. Eur Arch Paediatr Dent 2015;16:397-407.

[10] Moiseiwitsch JR. Position of the mental foramen in a North American, white population. Oral Surg Oral Med Oral Pathol Oral Radiol Endod 1998;85:457-460. .

[11] Green RM. The position of the mental foramen: a comparison between the southern (Hong Kong) Chinese and other ethnic and racial groups. Oral Surg Oral Med Oral Pathol 1987;63:287290.

[12] Balcioglu HA, Kilic C, Akyol M, Ulusoy AT. Horizontal migration of pre - and postnatal mental foramen: an anatomic study. Int J Pediatr Otorhinolaryngol 2011;75:1436-1441.

[13] He X, Jiang J, Cai W, Pan Y, Yang Y, Zhu K, Zheng Y. Assessment of the appearance, location and morphology of mandibular lingual foramina using cone beam computed tomography. Int Dent J 2016;66:272-279.

[14] Jacobs R, Mraiwa N, Van Steenberghe D, Sanderink G, Quirynen $M$. Appearance of the mandibular incisive canal on panoramic radiographs. Surg Radiol Anat 2004;26:329-333.

[15] Sekerci AE, Cantekin K, Aydinbelge M. Cone beam computed tomographic analysis of the shape, height, and location of the mandibular lingula in a population of children. Biomed Res Int 2013;2013:825453.

[16] Zhou C, Jeon T-H, Jun S-H, Kwon J-J. Evaluation of mandibular lingula and foramen location using 3-dimensional mandible models reconstructed by cone-beam computed tomography. Maxillofac Plastic Recons Surg 2017;39:1-7. 
[17] Caglayan F, Sumbullu MA, Akgul HM, Altun O. Morphometric and morphologic evaluation of the mental foramen in relation to age and sex: an anatomic cone beam computed tomography study. J Craniofac Surg 2014;25:2227-2230.

[18] Udhaya K, Saraladevi KV, Sridhar J. The morphometric analysis of the mental foramen in adult dry human mandibles: a study on the South Indian population. J Clin Diagn Res 2013;7:15471551.

[19] Makris N, Stamatakis H, Syriopoulos K, Tsiklakis K, van der Stelt PF. Evaluation of the visibility and the course of the mandibular incisive canal and the lingual foramen using cone-beam computed tomography. Clin Oral Implants Res 2010;21:766771.

[20] Andrei F, Motoc AG, Didilescu AC, Rusu MC. A 3D cone beam computed tomography study of the styloid process of the temporal bone. Folia Morphol (Warsz) 2013;72:29-35.

[21] Senel B, Ozkan A, Altug HA. Morphological evaluation of the mandibular lingula using cone-beam computed tomography. Folia Morphol (Warsz) 2015;74:497-502.

[22] Nicholson ML. A study of the position of the mandibular foramen in the adult human mandible. Anat Rec 1985;212:110112.

[23] Afsar A, Haas DA, Rossouw PE, Wood RE. Radiographic localization of mandibular anesthesia landmarks. Oral Surg Oral Med Oral Pathol Oral Radiol Endod 1998;86:234-241.

[24] Kim HJ, Lee HY, Chung IH, Cha IH, Yi CK. Mandibular anatomy related to sagittal split ramus osteotomy in Koreans. Yonsei Med J 1997;38:19-25.

[25] Shenoy V, Vijayalakshmi S, Saraswathi P. Osteometric analysis of the mandibular foramen in dry human mandibles. J Clin Diagn Res 2012;6:557-560.

[26] Samanta PP, Kharb P. Morphological analysis of the lingula in dry adult human mandibles of north Indian population. Journal of Cranio-Maxillary Diseases 2012;1:7-11.

[27] Sekerci AE, Sisman Y. Cone-beam computed tomography analysis of the shape, height, and location of the mandibular lingula. Surg Radiol Anat 2014;36:155-162.

[28] Kjaer I. Formation and early prenatal location of the human mental foramen. Scand J Dent Res 1989;97:1-7.
[29] Williams FL, Krovitz GE. Ontogenetic migration of the mental foramen in Neandertals and modern humans. J Hum Evol 2004;47:199-219.

[30] Gershenson A, Nathan H, Luchansky E. Mental foramen and mental nerve: changes with age. Acta Anat (Basel) 1986;126:21-28.

[31] Gungor E, Aglarci OS, Unal M, Dogan MS, Guven S. Evaluation of mental foramen location in the 10-70 years age range using cone-beam computed tomography. Niger J Clin Pract 2017;20:88-92.

[32] Neiva RF, Gapski R, Wang HL. Morphometric analysis of implant-related anatomy in Caucasian skulls. J Periodontol 2004;75:1061-1067.

[33] Apinhasmit W, Methathrathip D, Chompoopong S, Sangvichien S. Mental foramen in Thais: an anatomical variation related to gender and side. Surg Radiol Anat 2006;28:529-533.

[34] Mardinger O, Manor Y, Mijiritsky E, Hirshberg A. Lingual perimandibular vessels associated with life-threatening bleeding: an anatomic study. Int J Oral Maxillofac Implants 2007;22:127-131.

[35] Rosano G, Taschieri S, Gaudy JF, Testori T, Del Fabbro M. Anatomic assessment of the anterior mandible and relative hemorrhage risk in implant dentistry: a cadaveric study. Clin Oral Implants Res 2009;20:791-795.

[36] Liang X, Jacobs R, Lambrichts I, Vandewalle G. Lingual foramina on the mandibular midline revisited: a macroanatomical study. Clin Anat 2007;20:246-251.

[37] Mraiwa N, Jacobs R, Moerman P, Lambrichts I, van Steenberghe $D$, Quirynen M. Presence and course of the incisive canal in the human mandibular interforaminal region: two-dimensional imaging versus anatomical observations. Surg Radiol Anat 2003;25:416-423.

[38] Tepper G, Hofschneider UB, Gahleitner A, Ulm C. Computed tomographic diagnosis and localization of bone canals in the mandibular interforaminal region for prevention of bleeding complications during implant surgery. Int J Oral Maxillofac Implants 2001;16:68-72.

[39] Gahleitner A, Hofschneider U, Tepper G, Pretterklieber M, Schick $\mathrm{S}$, Zauza K, Watzek G. Lingual vascular canals of the mandible: evaluation with dental CT. Radiology 2001;220:186-189.

How to cite this article: Goller Bulut D, Bayrak S. Evaluation of the Position of Lingula Mandible, Mental Foramen and Lingual Foramen of Individuals in the 7-17 Age Groups Via Cone-Beam Computed Tomography. Clin Exp Health Sci 2021; 11: 375-380. DOI: 10.33808/ clinexphealthsci.702860 